Article

\title{
Design of a Sustainable and Efficient Transportation Station (SETS) Based on Renewable Sources and Efficient Electric Drives
}

\author{
Myungchin Kim ${ }^{1}$, Jeongtae Kim ${ }^{2}$ and Sungwoo Bae ${ }^{2, *}$ \\ 1 Agency for Defense Development, Daejeon 34186, Korea; abekim81@gmail.com \\ 2 Department of Electrical Engineering, Yeungnam University, Gyeongsan 38541, Korea; \\ current_god@naver.com \\ * Correspondence: sbae@yu.ac.kr; Tel.: +82-53-810-3095 \\ Academic Editor: Ka Lok Man \\ Received: 31 October 2016; Accepted: 28 November 2016; Published: 2 December 2016
}

\begin{abstract}
The need for reduction in power consumption for public facilities has increased after the occurrences of multiple blackout events. In an effort to enable the development of green and smart social infrastructure, this paper introduces a design for a sustainable and efficient transportation system (SETS). For this design, renewable power sources and efficient electric drives are considered to be crucial technologies. Considering the subway station as an illustrative example, a power system design that uses wind and solar energy as major power sources is studied. The adjustable speed electric drive system that uses synchronous reluctance machines for ventilation systems contributes to increasing the overall power consumption efficiency. The effectiveness of the proposed SETS system is verified through a set of various field measurement data and simulation results. While the verification results demonstrate that operation of SETS is enabled by effective integration of renewable sources and efficient ventilation systems, future research directions have also been identified.
\end{abstract}

Keywords: energy saving method; variable speed control; ventilation system; subway; renewable energy

\section{Introduction}

Energy conservation has been recognized as an important global issue with the rapid increase of energy consumption and higher interest for sustainability. Such concerns in various application sectors (e.g., commercial, industrial, and residential) have resulted in a need to develop sustainable and efficient approaches for production and consumption of electricity. Representative examples of such approaches include the development of electric vehicles [1], energy management systems [2], and energy-efficient buildings [3]. Regarding energy consumption, the public transportation sector also should not be overlooked. In particular, subway system operation requires energy not only for the rail locomotives, but also for the accompanying infrastructure that is required for passenger convenience and underground traffic control. For example, the metropolitan subway system in Korea consumed about 90,000 MWh in 2012 [4]. Because of the relatively large size of subway networks, especially in metropolitan areas, it is logical to expect an apparent increase in system efficiency by applying energy-efficient technologies to the subway systems.

To cope with this high energy consumption in the subway infrastructure, there have been multiple projects conducted worldwide with the objective of making the subway system operate in a more efficient way. For example, the SEAM4US (Sustainable Energy Management for Underground Stations) project [5] of Europe has been initiated to obtain electricity consumption savings for metro stations. Examples of approaches that have been considered include installation of various sensors and applications of real-time control [5]. The MTA (Metropolitan Transportation Authority) network, 
which services the eastern part of the United States, has also been conducting research on establishing directions for increasing sustainability [6]. Examples of directions include increasing the amount of power being produced by renewable sources (e.g., solar, wind and tidal) and use of efficient lighting systems [6]. Similar projects have also been carried out by the Seoul Urban Railway Corporation, which services the underground transportation of the Seoul Metropolitan Area. Various approaches, such as reducing the average operation time of ventilation systems [7] and effective use of regenerative breaking energy in locomotives, could be considered to realize an efficient transportation system. Considering that various approaches could be taken for different sub-systems (e.g., rail vehicle, supporting utilities, and traffic control) in an urban subway system, research has also been performed on the proposal of parameters that could be used to optimize or characterize efficiency improvement measures [8] or conducting comprehensive analysis among different energy saving approaches [9].

This paper introduces a design for a sustainable and efficient transportation station (SETS) based on integration of renewable sources and efficient power consumption of loads. As a representative case of transportation stations, the study considered subway stations as an illustrative application. Compared with other public transportation (e.g., taxis and buses), subway systems require substantial amounts of energy for infrastructure that supports operations. As shown in Figure 1, the benefits of operating a SETS would be maximized by increasing the use of renewable sources and consuming power in a more efficient manner. Although the intermittent output characteristics of renewable sources could make it a challenge to ensure stable energy supply, such challenges could be effectively addressed by combining different type of renewable sources, effective use of energy storage, and smart management of energy.

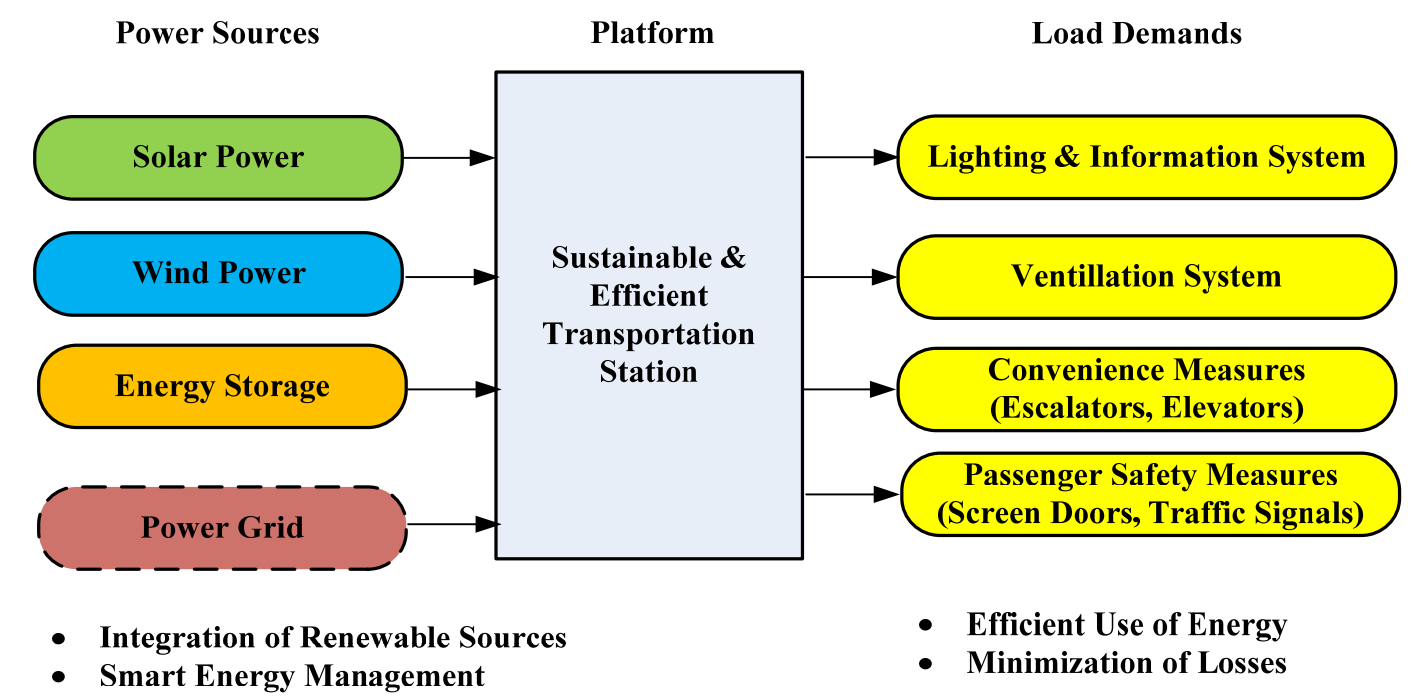

Figure 1. Concept of sustainable and efficient transportation station (SETS).

The remainder of this paper is organized as follows: Section 2 reviews related work that has been performed on renewable sources and efficient ventilation systems. The contributions of this paper are also highlighted. Section 3 studies the characteristics and modeling approach of the renewable sources that are considered in this paper (i.e., PV modules and wind generator). Approaches that could be considered for efficient power consumption in transportation ventilation systems are discussed in Section 4. Section 5 discusses the design and performance of a power system for a possible SETS configuration. Directions for future work have also been discussed based on the verification results. Lastly, Section 6 concludes this paper with a summary of findings. 


\section{Previous Work and Contributions}

As shown in Figure 1, integration of renewable sources and efficient use of electric loads are necessary for feasible development of a SETS. While it is necessary to apply various approaches for each type of load, the discussion in this paper focuses on improving the efficiency of ventilation systems. This approach is based on survey results from actual operation cases that indicate that ventilation equipment used about $45 \%$ of the total electricity consumption in subway stations [4]. In fact, a past demonstration performed by the Seoul Urban Railway Cooperation showed that it is possible to save about 3.6 million dollars in the ventilation sector's annual electricity cost by reducing the average operation time of ventilation systems [7]. However, simply reducing the operation time of ventilation systems can cause issues that are directly linked to the air quality [10]. Previous research in the literature [11,12] presented an economic analysis for effects of a blower motor replacement with a variable speed operation method to reduce the power consumption of the metropolitan subway station. This previous research $[11,12]$ demonstrated energy-saving effects based on the actual research data of the Suraksan subway station in Seoul, Korea. They concluded that an existing induction machine is required to be replaced with a Synchronous Reluctance Machine (SynRM) which is more energy-efficient than the existing induction machine, which becomes increasingly less efficient over time. While the results of $[11,12]$ demonstrated that the electric drives in ventilation systems could be configured to operate at a higher efficiency, an optimal system controller for ventilation systems has been studied in [13]. In [13], control of the ventilation system was performed according to the output of a controller that uses the MPC (Model Predictive Control) approach. With the proposed control approach, a satisfactory air quality level could be expected while minimizing the energy consumption. In [14], an operation approach for residential houses has been proposed. The ventilation ratio value switches between two distinct values (i.e., a high value and a low value) according to the air quality.

The other requirement for SETS realization is integration of renewable sources. PV panel installation has emerged as a feasible approach for residential homes [15]. In addition, use of renewable sources as a power source for buildings and other social infrastructure has been reported in various studies. Design and energy management approaches that have been considered for energy-efficient buildings has been reviewed in [3]. As reported in [3,16], installation of solar panels and wind turbines is a representative example of how urban buildings collect energy from renewable sources. Instead of simply installing renewable power sources in urban buildings, research has been done on which building configuration could maximize the utilization of wind energy [17] and solar energy [18]. In [19], the effect of dust on PV systems that are mounted in urban buildings have been investigated. Furthermore, use of renewable sources has also been reported for critical and industrial facilities. The research of [20] introduced a multi-objective optimization approach for a green data center that involves use of both renewable sources and conventional power sources. The study of [21] introduced a power architecture and power management approach for data centers that use both wind turbines and solar panels as a power source. With smart control of load demand, using renewable sources in data centers can become economically feasible [21]. A real-time control approach for factories with PV panel installation has also been proposed [22].

The contributions of this study can be summarized as follows. First, this study provides a comprehensive discussion on integration of various technologies required for design of energy-efficient public infrastructure. While the paper initiates the discussion by considering a subway station, the technical insights and analysis approach could be easily generalized for other similar public buildings and structures that require sustainability. Instead of focusing only on the integration of renewable sources or development of efficient ventilation systems, this paper covers both the aspects of power sources and loads for sustainable and efficient power systems. The discussion also includes the effect of practical constraints that should be considered to design a realistic power system for social infrastructure. Second, an intelligent control approach for ventilation systems is proposed. Although energy-saving methods were demonstrated by previous works [11,12], the fact that such methods usually consider a preprogrammed variable speed control method still introduces several 
disadvantages. Usually, speed torque patterns in the existing metropolitan subway station change hourly in order to provide good air quality to meet an air quality standard for the public transportation indoor environment. However, in general, the actual population density value in transportation stations cannot always match the predicted population density value that has been assumed for deriving the preprogrammed speed torque pattern. Hence, the preprogrammed speed torque pattern is subject to continuous modifications to maintain the air quality level. Such modifications might require extensive surveys with a large number of factors to be considered. If the difference between the predicted population density and the actual population density is relatively large, the ventilation system could perform too much or too little compared with the required electric drive system operation speed and period. Such operation would result in inefficient operation of the ventilation systems and even result in unsatisfactory air quality.

\section{Integration of Renewable Sources}

This study considered two renewable energy sources (i.e., wind generators and PV modules) for the design and operation of a SETS. To effectively deal with the output fluctuation of these renewable sources, this study also used batteries to form a dc distribution power system. Such a dc distribution power system was considered because renewable and alternative power sources could be connected to the integrated dc power network in a simpler manner than ac systems [23]. This section describes the modeling methodology that has been used in this study for the power output of wind generator and PV modules.

In this study, a permanent magnet synchronous machine (PMSM) that rotates at a variable speed control is used as the wind generator. The generator is controlled such that the output power follows the curve as shown Figure 2. Depending on the wind speed $(v)$, the output characteristics of the wind generator can be explained as follows. In case the wind speed is below the cut-in wind speed $\left(v<v_{\mathrm{c}}\right)$, the output of the wind generator is zero. If the wind speed is between the cut-in wind speed $\left(v_{\mathrm{c}}\right)$ and the rated wind speed $\left(v_{\mathrm{r}}\right), v_{\mathrm{c}}<v<v_{\mathrm{r}}$, the wind generator is controlled to operate at the maximum power point. This operation is enabled by controlling the machine to track the optimal power line as depicted in Figure 2. The optimal power line of a wind generator depends on the cube of wind speed as seen in $[24,25]$

$$
P_{\mathrm{g}}=\frac{1}{2} \eta_{\mathrm{g}} \eta_{\mathrm{R}} C_{\mathrm{pmax}} \rho \pi R^{2} v^{3}
$$

where $P_{\mathrm{g}}$ is wind generator output power, $\eta_{\mathrm{g}}$ is a wind generator power efficiency, $\eta_{\mathrm{R}}$ is a power conversion efficiency of a rectifier, $C_{\mathrm{p} \text { max }}$ is the maximum value of a rotor power coefficient, $\rho$ is the density of air, $R$ is a rotor radius, and $v$ is wind speed. Since the PMSM wind generator requires a rectifier that performs ac-dc power conversion, the power conversion efficiency of the rectifier is also considered in Equation (1). By assuming the blade angle pitch is $0^{\circ}$, the maximum value of the rotor power coefficient, $C_{\mathrm{p} \text { max }}$, can be determined as $[25,26]$

$$
C_{\mathrm{p}}=0.44 \sin \frac{\pi\left(\omega_{\mathrm{m}} R-2 v\right)}{13 v}
$$

where $\omega_{\mathrm{m}}$ is the mechanical rotor speed. For wind speed that is higher than the rated wind speed $\left(v>v_{\mathrm{r}}\right)$, the wind generator is controlled so that the output power is limited to the rated power value. Such an operation pattern is used to prevent possible damage in the wind turbine. If a detailed modeling approaches for a wind generator is required, previous studies [25] could be consulted. 


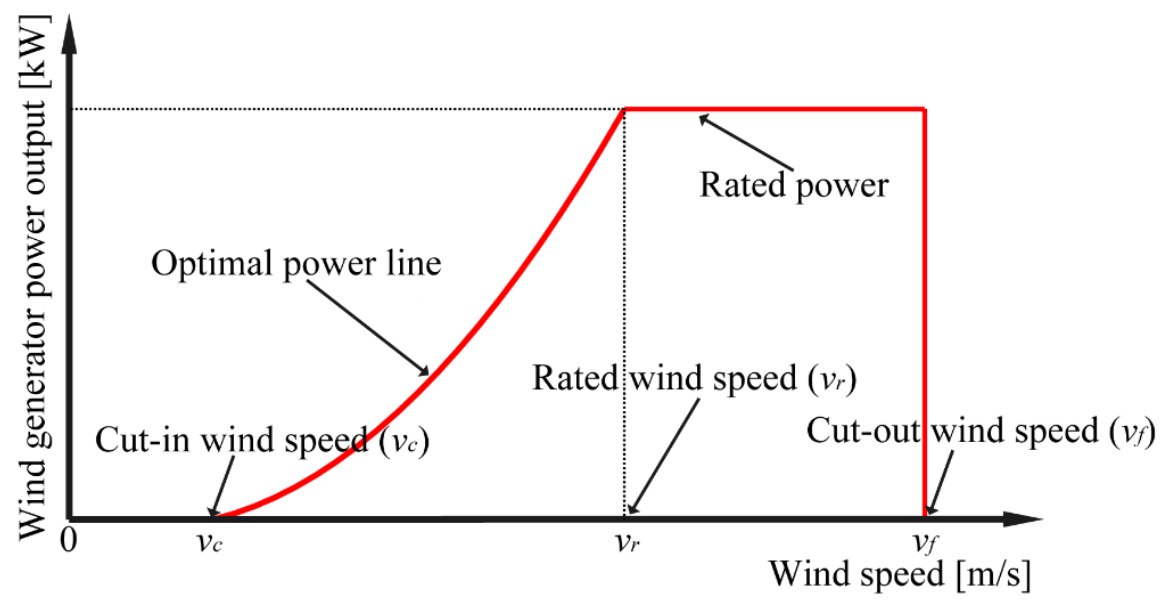

Figure 2. Variable speed control strategy for a wind generator.

For conversion of solar energy to electrical energy, PV modules are used in this paper. The output power of PV modules depends on the surface temperature $(T)$ and the solar irradiance level $(G)$. In order to maximize the amount of harvested energy, PV modules are usually controlled to operate at the maximum power point (MPP) [27]. While the exact output value of the PV modules would be affected by various factors (e.g., type of MPP tracking approach, hardware specifications of the system), the output power of a PV system $\left(P_{\mathrm{pv}}\right)$, which consists of a PV module and a power converter, can be approximated as [28-30]

$$
\begin{gathered}
P_{\mathrm{pv}}=\eta_{\mathrm{c}} V_{\mathrm{m}} I_{\mathrm{m}} \\
V_{\mathrm{m}} \approx V_{\mathrm{std}}+K_{\mathrm{v}}\left(T-T_{\mathrm{std}}\right) \\
I_{\mathrm{m}} \approx \frac{G}{G_{\mathrm{std}}} I_{\mathrm{std}}+K_{\mathrm{i}}\left(T-T_{\mathrm{std}}\right)
\end{gathered}
$$

where $V_{\mathrm{m}}$ and $I_{\mathrm{m}}$ are respectively the PV panel output voltage and current at the MPP, $T_{\text {std }}$ and $G_{\text {std }}$ are respectively the PV panel surface temperature and solar irradiance at the standard test condition (i.e., $25{ }^{\circ} \mathrm{C}$ and $1000 \mathrm{~W} / \mathrm{m}^{2}$ ), $V_{\text {std }}$ and $I_{\text {std }}$ are respectively the rated PV panel output voltage and current at the standard test condition which can be found in the manufacturer's datasheet, $K_{\mathrm{i}}$ and $K_{\mathrm{v}}$ are respectively the PV panel temperature coefficients, and $\eta_{\mathrm{c}}$ is the conversion efficiency of the power converter. Since a great deal of research has been conducted on detailed modeling of PV modules [31,32], an alternative PV module model could be considered depending on the required fidelity level.

\section{Design of Efficient Ventilation System}

For ventilation systems in subway stations, the electric drive configuration that uses an induction machine being controlled using a rather straightforward ON/OFF approach has been generally used [12]. The induction machine is operated at a constant speed whenever the machine controller receives an activation signal (i.e., ON signal) from a higher level controller.

Figure 3 shows the block diagram of such an electric drive system. Considering that the system consists of an electric machine, a power converter, and a controller, it is possible to improve the efficiency of the drive system by introducing changes to each of the sub-components (i.e., system controller law, power converter and electric machine). Examples of possible changes that could be considered for higher efficiency are listed next to each sub-component in Figure 3. 


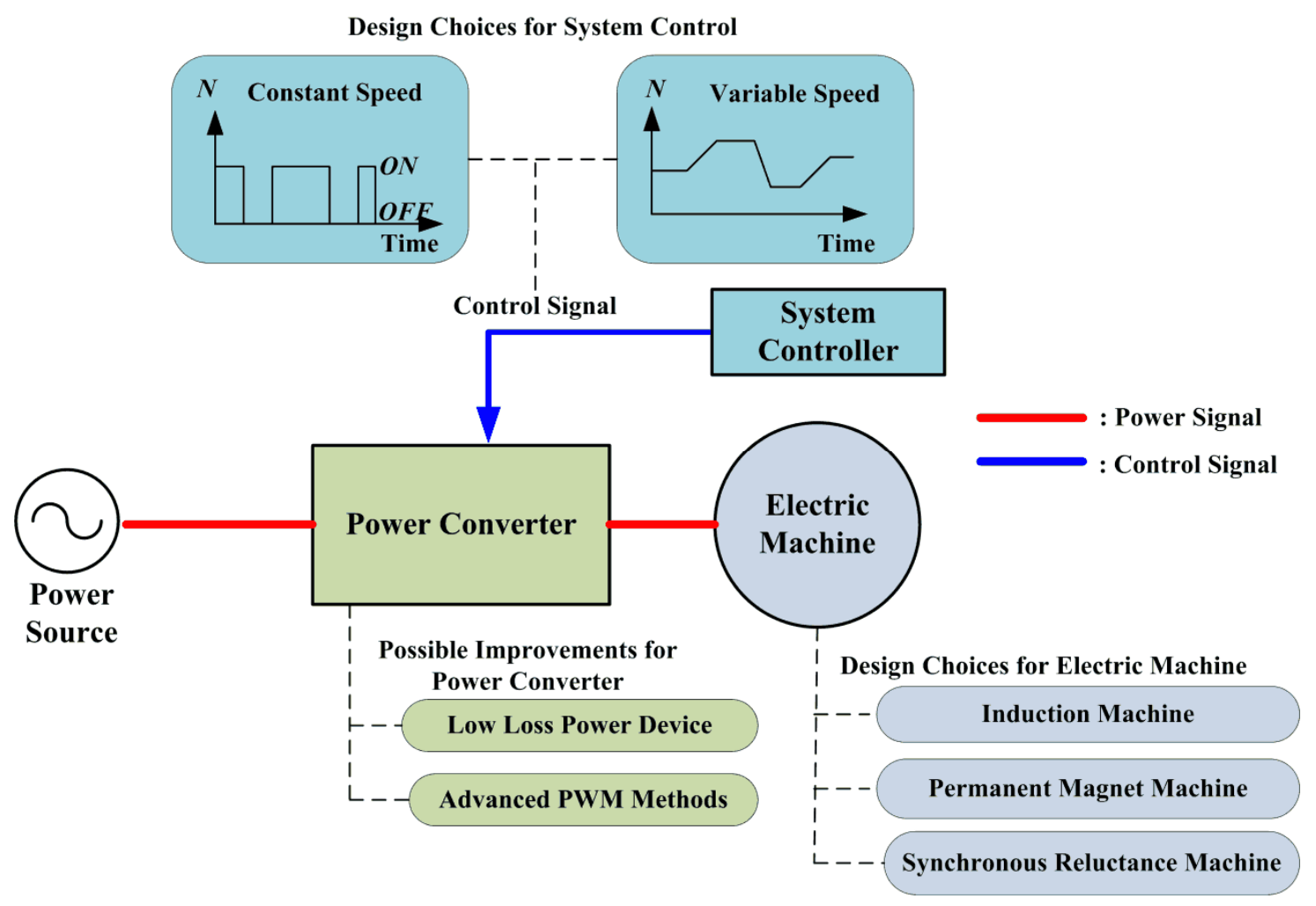

Figure 3. Block diagram of an electric drive system for ventilation systems and their design choices.

Examples of design alternatives that could be considered for the system control and the electric machine can be identified as shown in Figure 3, based on previous research. In particular, this paper focuses on the approaches introduced in [12]. According to [12], it has been demonstrated that the efficiency of electric drives in ventilation systems could be improved by introducing the capability to drive electric machines at various speeds. The main difference between the variable speed control approach and the conventional constant speed approach is that the electric machine can be operated at different speeds. While the constant speed approach considers only a single operation speed, the variable speed control approach considers a set of different machine speeds. In addition to changing the control approach, the use of SynRMs has also been proposed in [12] instead of using induction machines.

In case of SynRMs, the electromagnetic torque is generated as [33]

$$
T_{e}=1.5 \frac{P}{2}\left(L_{d}-L_{q}\right) i_{d s} i_{q s}
$$

where $P$ is the number of poles, $L_{d}$ is the d-axis inductance, $L_{q}$ is the q-axis inductance, $i_{d s}$ is the d-axis stator current, and $i_{q s}$ is the q-axis stator current. From Equation (6), the torque is determined by the difference between the two inductances $\left(L_{d}-L_{q}\right)$ and the stator current values. While the inductance difference is affected by how the machine is designed, the current values are the variables that should be controlled for the SynRM operation. A typical block diagram for a SynRM controller is shown in Figure 4 [34]. As shown in Figure 4, the speed of the SynRM can be controlled by using a cascaded control configuration. 


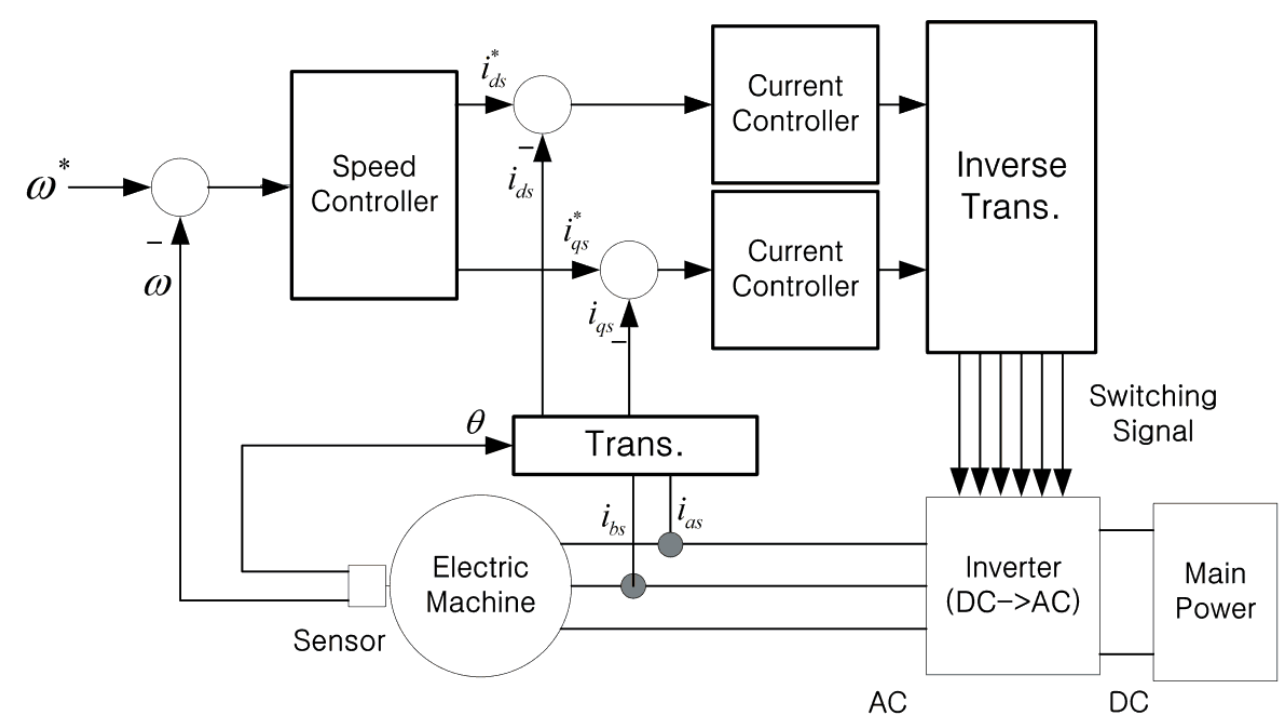

*. Trans.: From abc coordinate to da coordinate *. Inverse Trans.: From da coordinate to abc coordinate

Figure 4. Block diagram of a typical SynRM controller.

The approaches that could be considered for improving the electric drive efficiency can be categorized as shown in Table 1 [12]. Such categorization was performed depending on the machine type and the machine control approach. While a detailed comparison of power consumption for the cases in Table 1 has been discussed in [12], a summary of such comparison results is provided in this paper to highlight the importance of electric drive configurations (i.e., control approach and machine type) to the overall efficiency of SETS design and operation.

Table 1. Electric drive configuration candidates [12].

\begin{tabular}{ccc}
\hline & On/Off Control (Fixed Speed) & Variable Speed Control \\
\hline Induction Machine & Case 1 (IM_Const) & Case 2 (IM_Var) \\
Synchronous Reluctance Machine & Case 3 (SynRM_Const) & Case 4 (SynRM_Var) \\
\hline
\end{tabular}

Figure 5 shows the electricity price for cases 1,2, and 4 of Table 1 by using the power consumption data from [12] and electricity price data from the Korea Electric Power Corporation (KEPCO) [35].

\section{Electricity Cost (Unit: KRW)}

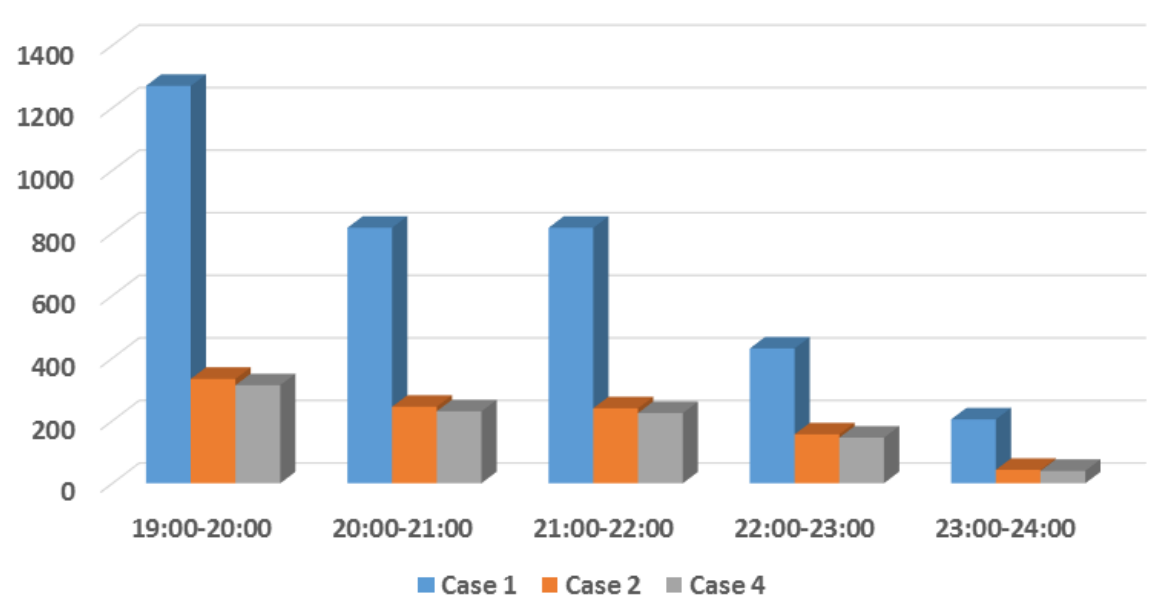

Figure 5. Electricity cost comparison of different electric drive configurations (based on [12,35]). 
The power consumption saving effect by the different speed control approaches can be studied by comparing the result of case 1 and case 2 . While both cases use an induction machine, significant savings can be achieved by adopting the variable speed control approach. During the period of 19:00-20:00, for example, nearly 73\% decrease in electricity cost was achieved. Especially, the difference in electricity prices during rush hours (i.e., 19:00-20:00) was higher than that of other time periods because the electric machine operation speed of the ventilation system was modified with large floating population in order to keep the indoor air quality management regulations for public transports [10].

The effect of different machines can be verified by comparing the results of case 2 and case 4 . Although the amount of energy savings might seem to be negligible compared with the difference caused by the changing the control approach (i.e., comparison between case 1 and case 2), such difference could still be non-negligible considering that such savings could be accumulated to a comparable level by considering the overall number of subway stations that exist in a subway network that services a wide and crowded metropolitan area. The results of Figure 5 show that meaningful energy savings can be achieved by simply changing the control approach from constant-speed on/off control to variable-speed control in the electric drives of ventilation systems. In case a new ventilation system has to be installed at a newly built station, furthermore, it is worth using a variable speed electric drive system equipped with SynRMs.

\section{Verification Results and Directions of Future Work}

In order to demonstrate that the variable speed approach in ventilation systems does not degrade the air quality level compared with the conventional constant speed approach, the particle pollution $\left(\mathrm{PM}_{10}\right)$ was measured for both control approaches. The measurement was performed at an actual subway station, Suraksan Station of the Seoul Metropolitan Subway System, from 19:00 to 23:30. The results of Figure 6 show that the particle pollution level is not degraded by adopting the variable speed approach. In fact, the maximum value of the particle pollution decreased by adopting the variable speed approach. While the maximum value of the particle pollution with the constant speed drive approach exceeded $70 \mathrm{ug} / \mathrm{m}^{3}$, the values of the variable speed approach did not exceed $60 \mathrm{ug} / \mathrm{m}^{3}$ throughout the overall measurement period. The results of both Figure 5 (i.e., power consumption comparison) and Figure 6 (i.e., air quality comparison) show that the variable speed approach can provide satisfactory air quality performance in a more efficient manner.

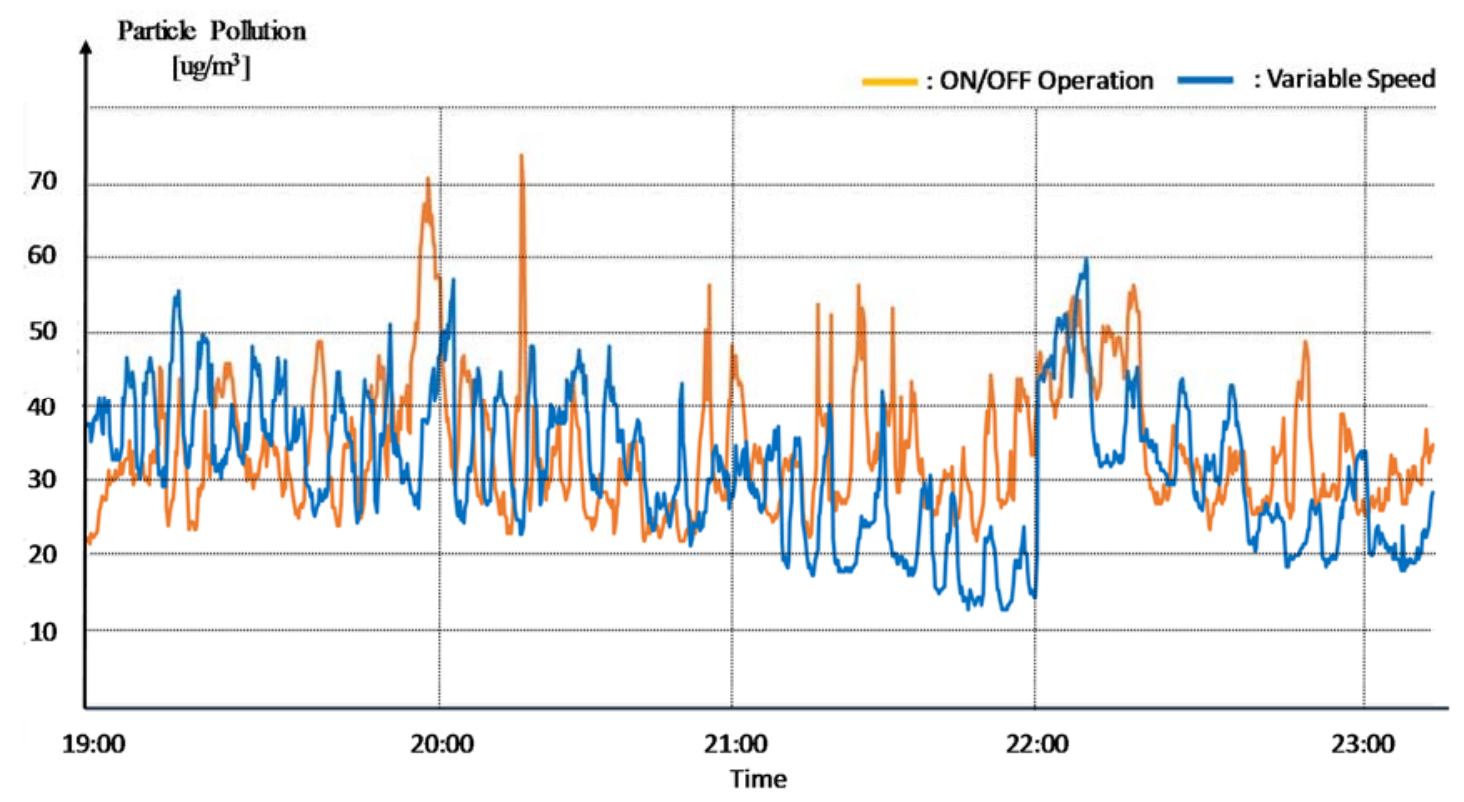

Figure 6. Comparison of particle pollution depending on control strategies. 
Figure 7 shows the SETS power system configuration that was considered for simulation. The voltage level of the main bus is $380 \mathrm{~V}$ similar to previous studies [36,37]. The PV modules and the wind generator have been considered sustainable power sources, while the battery was used as energy storage. In this simulation, it was assumed that $60 \mathrm{PV}$ modules and two wind generators were installed in the SETS. The datasheet parameter values of a commercially available product [38] were used for modeling the PV module. According to [38], the output power of each PV module is $200 \mathrm{~W}$ at standard test conditions (temperature: $25^{\circ} \mathrm{C}$, irradiance: $1000 \mathrm{~W} / \mathrm{m}^{2}$ ). For the wind generator, it was assumed that a $12.8 \mathrm{~kW}, 12$-pole permanent magnet synchronous generator (PMSG) that has a blade radius of $3 \mathrm{~m}$ was used. Since the energy storage should be able to discharge and charge power depending on the power balance of the system (i.e., difference between the load power and the source power), the power flow of the battery is expected to be bi-directional as depicted in Figure 7. While it is possible to connect the battery through a power converter, the simulation of this paper was conducted using a configuration without such converter. In this study, it was also assumed that the SETS could receive power from the main grid. This power transfer can ensure that the SETS loads could still be powered if the output of the renewable sources is extremely low.

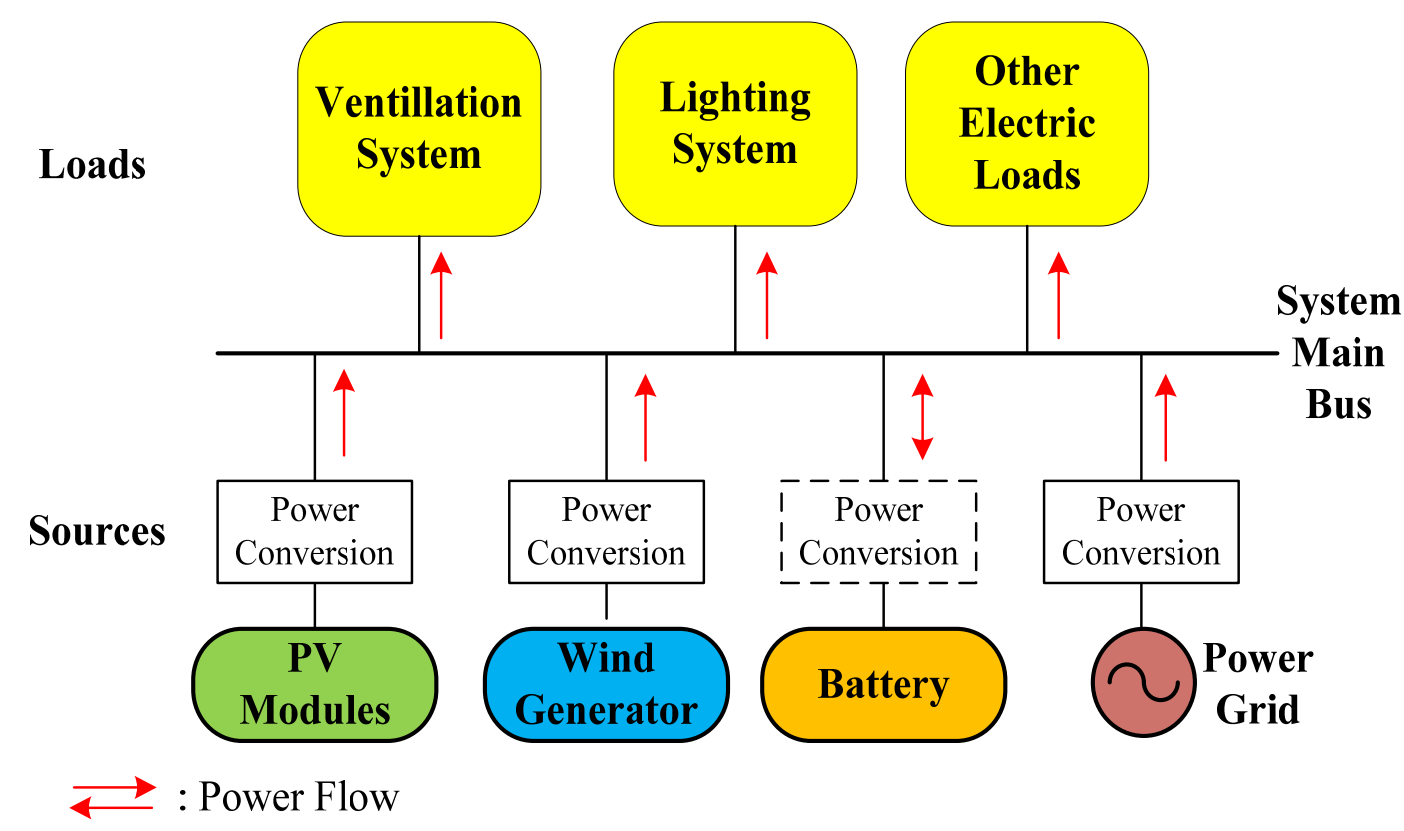

Figure 7. Configuration of a simulated SETS power system.

Power management of the system was performed such that the renewable sources transfer the maximum available power, while the power balance of the system is maintained by controlling the power flow of the battery and the power grid. Since the renewable sources are operated to maximize the power production, it is possible to minimize the amount of power that should be transferred from other sources. While both the battery and the power grid contribute to system power balance, the specific level of contributions between the two sources could vary depending on the power management approach. For example, it is possible to minimize the power grid's involvement in power balance by maximizing the battery power command. The power transfer from the grid is only activated when the required amount of power flow for balanced operation surpasses the battery capacity. Such an approach could achieve an effect that decreases the dependence of the SETS on the power grid. If battery usage should be minimized, power management could be performed such that the amount of grid power transfer is maximized. Either management approach could be applied depending on the operation objective and condition of the overall SETS. 
Figure 8 shows the solar irradiation, wind speed and load power profiles that were considered. The intermittent characteristics of a renewable power source can be observed from the fluctuation of the wind speed and irradiation profile. Instead of a fixed load profile, an exemplary load profile that experiences a step-wise change for every $10 \mathrm{~min}$ was assumed in the simulation. This profile was used to reflect that it is more realistic for the load consumption to show a variation throughout a day. For example, the amount of air circulation that should be handled by the ventilation system would be higher in crowded periods (e.g., rush hours) compared with periods in the early morning or late night.
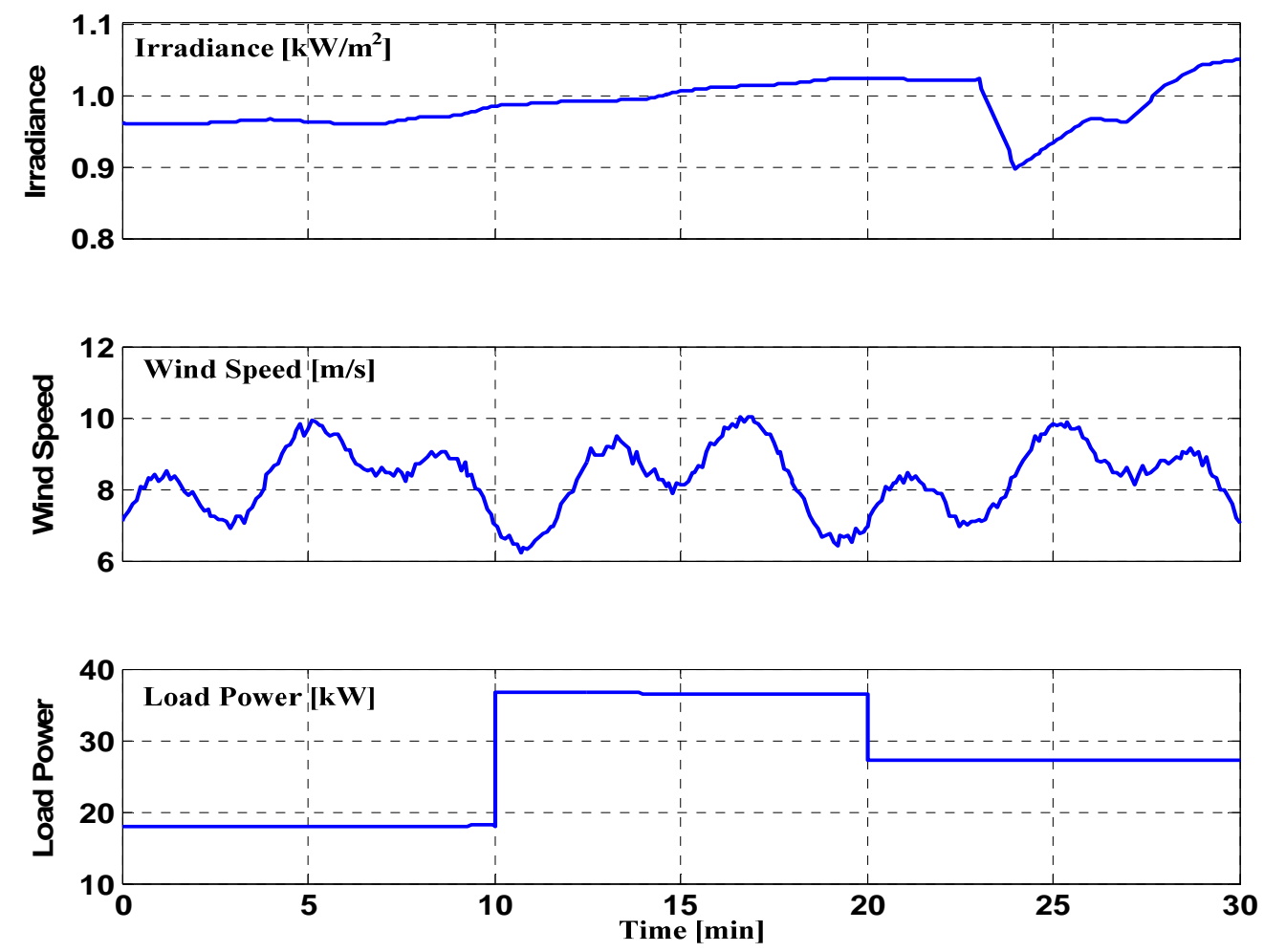

Figure 8. Profile of simulated solar irradiance, wind speed and load power.

The power waveforms of PV modules, wind generator, battery and the grid connection are shown in Figure 9. The outputs of renewable sources were calculated based on Equation (1), Equation (3) and the profile data of Figure 8 (i.e., wind speed and solar irradiation). From $t=0$ min to $t=10 \mathrm{~min}$, both renewable sources generate electric power according to the irradiance data and wind speed data. In order to maintain the battery charge level above a certain level, it was assumed that the SETS power system receives about $5.7 \mathrm{~kW}$ from the grid. As the sum of the source power is larger than the load power, the battery is being charged as shown by the negative battery power in Figure 9 . Once the load power increases at $t=10 \mathrm{~min}$, it can be seen that the battery experiences a discharge depicted as the positive battery power in Figure 9. Since the PV power, the wind power, and the grid power do drastically increase compared with the load power, the battery must be discharged so that the load operation is not interrupted by the increased load demand. Despite the increase in the load level, the power loads were able to operate without importing power from the electric grid. While it was possible to consider power import from the electric grid, such a battery discharge approach was applied to decrease the reliance on the power grid for SETS operation. As the load power decreases at $t=20 \mathrm{~min}$, the battery still experiences a discharge. Since the required load power is smaller compared with the previous load level (i.e., from $t=10 \mathrm{~min}$ to $t=20 \mathrm{~min}$ ), the discharge takes place at a lower rate compared with the previous time period. During this time period, the SETS power system receives support from the power grid as shown in the grid power waveform. Although the sum of the wind power and the PV power is lower than the required load power, both the battery and the grid involve 
in supplying the deficient power to the load. While the involvement of the grid could have been prevented as in the previous period, such an approach was not considered in this period to prevent the battery charge level from experiencing a relatively low level caused by continuous discharging.
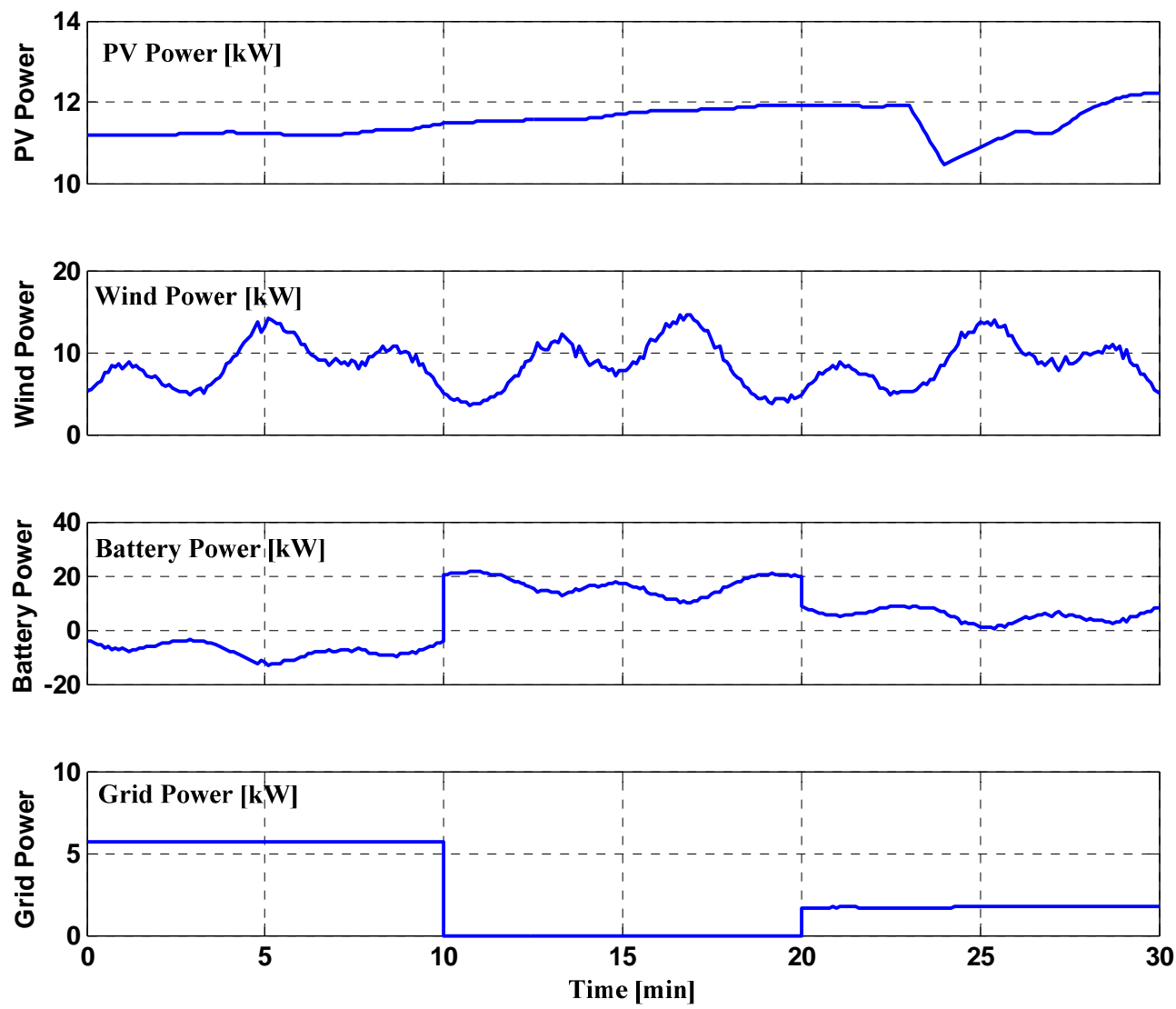

Figure 9. Simulation results of the considered SETS configuration.

It is worth noting that the SETS power system does not always require support from the power grid. Through effective operation of the battery, it is possible to reduce the amount of power that has to be imported from the grid. While the SETS was able to operate without any grid power from $t=10 \mathrm{~min}$ to $t=20 \mathrm{~min}$, the level of power that is imported from the grid could be reduced from $t=20 \mathrm{~min}$ to $t=30 \mathrm{~min}$ based on the discharge of the battery. Such observations show that proper design and optimal power management of SETS could enable implement design of a SETS system that requires minimal support from the power grid. In fact, the effect of the operation principles of the power management approach could be highlighted by comparing the waveforms between the period from $t=10 \mathrm{~min}$ to $t=20 \mathrm{~min}$ and the period from $t=20 \mathrm{~min}$ to $t=30 \mathrm{~min}$. Although the required load power value was larger than the sum of the renewable sources in both periods, the grid power transfer was only activated from $t=20 \mathrm{~min}$ to $t=30 \mathrm{~min}$. In the simulation considered in this study, this difference was caused by considering also the minimum charge level of the battery. If other factors (e.g., different power losses of various transmission paths, availability of power grid and battery usage period) were also considered in the power management algorithm, different operation behaviors of the SETS power system to power imbalances could have occurred.

While the results of Figure 9 were obtained from an illustrative example, it is worth noting that such results could vary depending on a number of factors. First, the configuration (e.g., type of renewable energy source, ratings, and physical size) of the renewable sources is expected to be strongly dependent to the geographical features of each individual station. For example, the feasible space for PV module installation might depend on whether the station is located entirely under the 
ground or constructed above the ground. It might be expected that the latter case is more economical when considering a higher utilization of PV modules compared to the former case. Similar constraints could also affect wind generator installation. For locations that are less crowded (e.g., suburban neighborhoods or satellite cities of a metropolitan transportation network), it could be possible to expect a higher power yield from wind energy by considering larger wind blades and more installation of wind generators. Another factor to be considered is the continuous progress in novel energy harvesting technologies and efficient electric drives. For example, an approach that uses the wind generated from the train movement as a source for generating electricity has been reported [39]. Such approaches would increase the options for energy generation and their effective aggregation could result in lowering the reliance on the power grid to handle cases with high load consumptions.

From the verification results, directions for necessary future work on SETS design and operation have been identified. Detailed development of an intelligent ventilation control approach and an integrated energy management approach are to be conducted. First, an intelligent ventilation control approach that considers both efficiency and air quality is to be developed by considering a control strategy that responds directly to the air quality level. The block diagram of such an approach is shown in Figure 10.

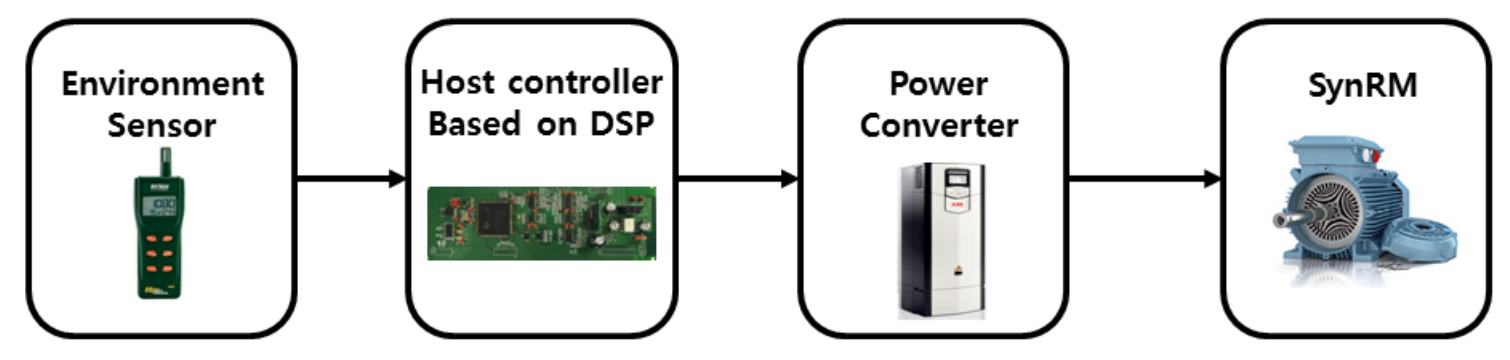

Figure 10. Intelligent host control scheme for variable speed control.

The most distinct difference of the proposed approach is that the machine speed is directly determined by the air quality information (i.e., particle pollution) measured by an environmental sensor. For instance, consider a case when the floating population in the subway station increases during rush hours. The air quality of a station is expected to drop and the electric machine would be required to operate at a faster speed. Specifically, the intelligent host controller increases a magnitude of a current control signal to satisfy the air quality regulation as shown in Figure 3. If the air quality satisfies the threshold value of environmental regulations, the present current control signal value remains constant. On the other hand, if air quality is lower or higher than the guideline, the current signal value should respectively increase or decrease via the feedback process of the intelligent host controller. This current control signal is fed to an electric drive system for controlling the SynRM speed. Although the proposed approach might seem to be similar to the variable speed approaches of Table 1, the operation speed in the proposed approach is determined by the air quality. In cases 2 and 4 of Table 1, the operation speed is determined not by real time feedback of the air quality, but rather follows a predefined speed command pattern.

Second, a comprehensive energy management approach that considers not only integration of renewable sources and efficient ventilation system but also other potential power sources and electric loads of transportation stations is needed. While the discussion of this paper has focused on ventilation systems, it is worth noting that other types of loads also consume a non-negligible amount of electric power. Examples of such loads include lighting, traffic control, and passenger convenience. An important direction that should also be considered is identification and management of potential power sources that could be effectively used for increasing the power supply. For instance, the braking power of subway vehicles could be used to support operation of each station where the subway makes a stop. By managing such power sources, it is even possible to consider subway vehicles to be energy storage devices with mobility that could transfer power between adjacent SETSs. Effective use of 
battery power inside electric vehicles that are parked by commuters near the station is also an avenue to be studied. While the power level of each of the considered potential sources might seem to be trivial, the aggregate values are expected to be considerable based on the number of transportation stations that exist in a metropolitan area. Through development of smart energy management approaches that effectively manage the various power sources and electric loads, it is possible to perform economic operation and sizing of a SETS.

\section{Conclusions}

This paper explored a design approach for sustainable and efficient transportation stations (SETSs) by integrating existing technologies for renewable energy sources and efficient electric drives. The design, control and modeling of both the renewable power sources and the efficient electric drive were discussed. Regarding the renewable power source, the use of solar energy and wind energy was considered. For efficient load consumption, the possibility of increasing efficiency by adopting a variable-speed drive approach and synchronous reluctance machine was studied. The performance of a variable-speed-based ventilation system was verified based on actual measurements at a station. It was shown that it is possible to achieve both satisfactory air quality and significant savings in electricity by using the proposed electric drive approach. An intelligent ventilation system control approach was also proposed. In order to observe the operation of a SETS power system, an illustrative configuration that involves connection of PV modules, a wind generator, a battery and the power grid was considered for simulation. While the system performance could differ depending on the configuration details of each transportation station, it was shown that such a SETS power system could be designed. Directions for future research have also been identified. Because of the large number of power sources and electrical loads that make up a transportation system, the need to develop an advanced energy management approach that performs optimized power flow between different sources and loads has been highlighted. An intelligent control approach that directly responds to the air quality level in a more power-efficient manner would also contribute to increasing the overall system efficiency.

Acknowledgments: This work was supported by the 2016 Yeungnam University Research Grant.

Author Contributions: Myungchin Kim, Jeongtae Kim and Sungwoo Bae contributed to the literature review, the variable speed control comparison study, the intelligent control study, and manuscript preparation.

Conflicts of Interest: The authors declare no conflict of interest.

\section{References}

1. Boulanger, A.G.; Chu, A.C.; Maxx, S.; Waltz, D.L. Vehicle Electrification: Status and Issues. IEEE Proc. 2011, 99, 1116-1138. [CrossRef]

2. Lee, S.; Kwon, B.; Lee, S. Joint Energy Management System of Electric Supply and Demand in Houses and Buildings. IEEE Trans. Power Syst. 2014, 29, 2804-2812. [CrossRef]

3. Lu, Y.; Wang, S.; Shan, K. Design Optimization and optimal control of grid-connected and standalone nearly/net zero energy buildings. Appl. Energy 2015, 155, 463-477. [CrossRef]

4. Choe, S.-H. A Study on the Integrated LCCA/LCA Model for Introducing High Efficient Motors into Air Ventilation Systems of Public Facilities. Master's Thesis, Department of Architectural Engineering, Hanyang University, Seoul, Korea, 2015.

5. Sustainable Energy Management for Underground Stations (SEAM4US). Available online: http://seam4us. eu/index.php?p=71 (accessed on 27 October 2016).

6. Greening Mass Transit \& Metro Regions: The Final Report of the Blue Ribbon Commission on Sustainability and the MTA. Available online: http:/ /www.mta.info/environment (accessed on 27 October 2016).

7. Seoul Metropoilitan Rapid Transit. White Paper on Energy Saving; Modern Culture Press: Seoul, Korea, 2007.

8. Gonzalez-Gil, A.; Palacin, R.; Batty, P. Optimal energy management of urban rail systems: Key performance indicators. Energy Convers. Manag. 2015, 90, 282-291. [CrossRef] 
9. Gonzalez-Gil, A.; Palacin, R.; Batty, P.; Powell, J.P. A systems approach to reduce urban rail energy consumption. Energy Convers. Manag. 2014, 80, 509-524. [CrossRef]

10. Korea Ministry of Environment. Public Transport Indoor Air Quality Management Guidelines; Korea Ministry of Environment: Sejong-si, Korea, 2006.

11. Bae, S.; Kim, J. Ventilation System Energy Consumption Simulator for a Metropolitan Subway Station. In Proceedings of the 2015 International Conference on Information, System and Convergence Applications, Kuala Lumpur, Malaysia, 24-27 June 2015; pp. 1-2.

12. Bae, S.; Kim, J.; Yun, J. Energy Efficient Blower Control Strategy for the Ventilation System of a Metropolitan Subway Station. Indian J. Sci. Technol. 2015, 8, IPL0523(1)-IPL0523(6). [CrossRef]

13. Liu, H.; Lee, S.; Kim, M.; Shi, H.; Kim, J.T.; Wasewar, K.L.; Yoo, C. Multi-objective optimization of indoor air quality control and energy consumption minimization in a subway ventilation system. Energy Build. 2013, 66, 553-561. [CrossRef]

14. Nielsen, T.R.; Drivsholm, C. Energy efficient demand controlled ventilation in single family houses. Energy Build. 2010, 42, 1995-1998. [CrossRef]

15. Mountain, B.; Szuster, P. Solar, Solar Everywhere: Opportunities and Challenges for Australia's Rooftop PV Systems. IEEE Power Energy Mag. 2015, 13, 53-60. [CrossRef]

16. Li, Q.S.; Shu, Z.R.; Chen, F.B. Performance assessment of tail building-integrated wind turbines for power generation. Appl. Energy 2016, 165, 777-788. [CrossRef]

17. Toja-Silva, F.; Lopez-Garcia, O.; Peralta, C.; Navarro, J.; Cruz, I. An empirical-heuristic optimization of the building-roof geometry for urban wind energy exploitation on high-rise buildings. Appl. Energy 2016, 164, 769-794. [CrossRef]

18. Yang, T.; Zhang, X. Benchmarking the building energy consumption and solar energy trade-offs of residential neighborhoods on Chongming Eco-Island, China. Appl. Energy 2016, 180, 792-799. [CrossRef]

19. Lu, H.; Lu, L.; Wang, Y. Numerical investigation of dust pollution on a solar photovoltaic (PV) system mounted on an isolated building. Appl. Energy 2016, 180, 27-36. [CrossRef]

20. Lei, H.; Wang, R.; Zhang, T.; Liu, Y.; Zha, Y. A multi-objective co-evolutionary algorithm for energy-efficient scheduling on a green data center. Comput. Oper. Res. 2016, 75, 103-107. [CrossRef]

21. Iverson, Z.; Achuthan, A.; Marzocca, P.; Aidun, D. Optimal design of hybrid renewable energy systems (HRES) using hydrogen storage technology for data center applications. Renew. Energy 2013, 52, $79-87$. [CrossRef]

22. Ghadimi, P.; Kara, S.; Kornfeld, B. Renewable energy integration into factories: Real-time control of on-site energy systems. CIRP Ann. Manuf. Technol. 2015, 64, 443-446. [CrossRef]

23. Planas, E.; Andreu, J.; Garate, J.I.; de Alegria, I.M.; Ibarra, E. AC and DC technology in microgrids: A review. Renew. Sustain. Energy Rev. 2015, 43, 726-749. [CrossRef]

24. Murdoch, A.; Winkelman, J.R.; Javid, S.H.; Barton, R.S. Control Design and Performance Analysis of a $6 \mathrm{MW}$ Wind Turbine-Generator. IEEE Trans. Power Appl. Syst. 1983, PAS-102, 1340-1347. [CrossRef]

25. Bae, S.; Kwasinski, A. Dynamic Modeling and Operation Strategy for a Microgrid with Wind and Photovoltaic Resources. IEEE Trans. Smart Grid 2012, 3, 1867-1876. [CrossRef]

26. Kim, S.-K.; Jeon, J.-H.; Cho, C.-H.; Ahn, J.-B.; Kwon, S.-H. Dynamic Modeling and Control of a Grid-Connected Hybrid Generation System With Versatile Power Transfer. IEEE Trans. Ind. Electron. 2008, 55, 1677-1688. [CrossRef]

27. Subudhi, B.; Pradhan, R. A comparative Study on Maximum Power Point Tracking Techniques for Photovoltaic Power Systems. IEEE Trans. Sustain. Energy 2013, 4, 89-98. [CrossRef]

28. Villalva, M.; Gazoli, J.; Filho, E. Comprehensive approach to modeling and simulation of photovoltaic arrays. IEEE Trans. Power Electron. 2009, 24, 198-208. [CrossRef]

29. Coelho, R.; Concer, F.; Martins, D. A MPPT approach based on temperature measurements applied in PV systems. In Proceedings of the 9th IEEE/IAS International Conference on Industry Applications 2010, Sao Paulo, Brazil, 8-10 November 2010; pp. 1-6.

30. Sera, D.; Teodorescu, R.; Rodriguez, P. PV panel model based on datasheet values. In Proceedings of the 2007 IEEE International Symposium on Industrial Electronics 2007, Vigo, Spain, 4-7 June 2007; pp. 2392-2396.

31. Molina-Garcia, A.; Guerrero-Perez, J.; Bueso, M.C.; Kessler, M.; Gomez-Lazaro, E. A New Solar Module Modeling for PV Applications Based on a Symmetrized and Shifted Gompertz Model. IEEE Trans. Energy Conversion. 2015, 30, 51-59. [CrossRef] 
32. Silva, E.A.; Bradaschia, F.; Cavalcanti, M.C.; Nascimento, A.J. Parameter Estimation Method to Improve the Accuracy of Photovoltaic Electrical Model. IEEE J. Photovolt. 2016, 6, 278-285. [CrossRef]

33. Liu, H.-C.; Kim, I.-G.; Jeong, J.-M.; Lee, J. Study on the High Efficiency Design of IE4 Synchronous Reluctance Motor Replacing IE3 Induction Motor. Trans. Korean Inst. Electr. Eng. 2016, 65, 411-418. [CrossRef]

34. IEEE Industrial Drives Committee. Synchronous Reluctance Motors and Drives: A New Alternative; IEEE: Piscataway, NJ, USA, 1994.

35. Electric Rates Table for Industrial Service (Korean Electric Power Corporation). Available online: http:/ / cyber.kepco.co.kr/ckepco/front/jsp/CY/E/E/CYEEHP00203.jsp (accessed on 27 October 2016).

36. Inamori, J.; Hoshi, H.; Tanaka, T.; Babasaki, T.; Hirose, K. 380-VDC power distribution system for 4-MW-scale cloud facility. In Proceedings of the 36th IEEE International Telecommunications Energy Conference (INTELEC) 2014, Vancouver, BC, Canada, 28 September-2 October 2014; pp. 1-8.

37. $380 \mathrm{Vdc}$ Architectures for the Modern Data Center (Emerge Alliance). Available online: https://datacenters. lbl.gov/sites/all/files/380VdcArchitecturesfortheModernDataCenter.pdf (accessed on 20 November 2016).

38. KC 200GT Specification Sheet. Available online: http://www.kyocera.com.sg/products/solar/pdf/kc200gt. pdf (accessed on 27 October 2016).

39. Metro Explores New Green Energy Options: Placing a Wind Turbine in a Subway Tunnel. Available online: http:/ / thesource.metro.net/2014/03/31/metro-explores-new-green-energy/ (accessed on 27 October 2016).

(c) 2016 by the authors; licensee MDPI, Basel, Switzerland. This article is an open access article distributed under the terms and conditions of the Creative Commons Attribution (CC-BY) license (http:/ / creativecommons.org/licenses/by/4.0/). 